\title{
Optimal aNtiplatelet pharmacotherapy guided by bedSIDE genetic or functional TESTing in elective PCI patients: A pilot study: ONSIDE TEST pilot
}

\author{
Lukasz Koltowski ${ }^{1 *}$, Mariusz Tomaniak ${ }^{1 *}$, Daniel Aradi $^{2}$, Zenon Huczek ${ }^{1}$, \\ Krzysztof J. Filipiak $^{1}$, Janusz Kochman ${ }^{1}$, Pawel Balsam ${ }^{1}$, Sylwia Gajda ${ }^{1}$, Grzegorz Opolski ${ }^{1}$ \\ ${ }^{1} 1^{\text {st }}$ Department of Cardiology, Medical University of Warsaw, Poland \\ ${ }^{2}$ Heart Center, Balatonfüred, Hungary
}

\begin{abstract}
Background: Dual antiplatelet therapy (DAPT) is recommended after elective percutaneous coronary intervention (PCI) in stable coronary artery disease (SCAD) patients; however, still one-third of patients do not obtain adequate platelet inhibition that may result in increased cardiovascular risk. The aim of the ONSIDE TEST study is to evaluate the clinical impact of point-of-care genotyping-and platelet function-based personalized dual antiplatelet strategies in SCAD individuals undergoing PCI.

Methods: Fifty patients were randomized to one of the three study arms: 1) genotyping, 2) platelet function testing (PFT) and 3) control. Patients were tested with point-of-care Spartan RX CYP2C19 System (group 1) and VerifyNow $P 2 Y_{12}$ assay (group 2). In cases of inadequate response to clopidogrel, a loading dose of prasugrel was administered before PCI. The main clinical endpoint is the incidence of periprocedural myocardial injury (PMI).

Results: Five (32\%) patients in the genotyping arm and two (13\%) in the in the PFT arm were identified as poor clopidogrel metabolizers. The periprocedural platelet reactivity was significantly lower in the genotyping $(80 \pm 49.0 \mathrm{PRU})$ and PFT $(36.5 \pm 47 \mathrm{PRU})$ arms as compared to the control arm (176 $\pm 67.8 P R U), p=0.01$ and $p=0.03$, respectively. PMI appeared in $17(37 \%)$ patients of the entire study population.

Conclusions: Personalized DAPT results in an improved platelet inhibition. Apart from genotyping and aggregometry, it is feasible to integrate into everyday clinical practice PMI rates which are relevant when comparing different strategies. (Cardiol J 2017; 24, 3: 284-292)
\end{abstract}

Key words: platelet aggregation inhibitors, platelet testing, clopidogrel, prasugrel, pharmacotherapy individualization

\section{Introduction}

Percutaneous coronary interventions (PCI) with the implantation of new-generation drug-eluting stents (DES) or bioresorbable scaffolds improves symptoms, reduces the risk for recurrent ischemic events and improves quality of life in patients with stable coronary artery disease (SCAD) [1-3] and verified ischemia. However, procedure- related complications including stent thrombosis, distal embolization and vessel dissection still occur and may lead to peri-procedural myocardial injury or infarction with an elevation of cardiac enzymes (i.e. creatine kinase muscle-brain [CK-MB], cardiac troponin T [cTnT] and I [cTnI]) in $20-30 \%$ of patients [4-6]. Dual antiplatelet therapy (DAPT) has proved to reduce these subsequent risks, although the efficacy of the currently recommended

Address for correspondence: Lukasz Koltowski, MD, PhD, $1^{\text {st }}$ Department of Cardiology, Medical University of Warsaw, ul. Banacha 1a, 02-097 Warszawa, Poland, tel/fax: +48 2259919 51, e-mail: lukasz@koltowski.com

*L. Koltowski and M. Tomaniak contributed equally to the manuscript.

Received: 10.10.2016

Accepted: 26.01.2017 
pharmacotherapy regime in SCAD, i.e. clopidogrel plus aspirin, is characterized by a large variability in the response of individual patients expressed by low platelet inhibition identified in $22-43 \%$ of the population [7-9]. By means of platelet function testing and genotyping, it is possible to identify patients who do not adequately respond to DAPT $[10,11]$. In PCI patients treated with clopidogrel carriage of even one reduced-function CYP2C19 allele (*2), there is an apparent association with a significantly increased risk of major adverse cardiovascular events (MACE), particularly stent thrombosis [11]. Hypothetically these individuals might be suitable candidates for more potent antiplatelet agents (prasugrel, ticagrelor) that are characterized by even stronger platelet inhibition and an ability to overcome high on-treatment platelet reactivity $[12,13]$. The new generation rapid, easyto-use, point-of-care diagnostic testing-systems appear to be a promising solution with the potential to present advantages of advanced genotyping and platelet function testing (PFT) into everyday clinical practice. To date, this personalized approach to periprocedural DAPT, although appealing, it has been difficult to implement in routine practice due to technical and logistic circumstances. In addition, results of previous large clinical trials focusing on hard clinical endpoints did not support the concept of individualization of antiplatelet therapy in low risk populations with SCAD.

Nevertheless, the more potent $\mathrm{P}_{2} \mathrm{Y}_{12}$ inhibitors successful implementation into the clinical practice of PCI in an acute coronary syndrome setting remains vastly unexplored among patients undergoing elective PCI, and are also at risk of periprocedural ischaemic complications. In the era of a wide access to the best-in-class DES it may be not feasible to conduct a study evaluating prasugrel or ticagrelor among stable angina subjects that would be powered for clinical endpoint. Thus, an approach to demonstrate the impact of antiplatelet therapy modification on myocardial injury expressed by biomarker leakage might constitute an efficient option to address this issue.

Given this background, the ONSIDE TEST project was initiated (Optimal aNtiplatelet pharmacotherapy guided by bedSIDE genetic or functional TESTing in elective PCI patients) - an investigator-initiated, phase IV, multicenter, prospective, open-label, randomized controlled clinical trial (NCT01930773), aimed to assess the efficacy of point-of-care genotyping and PFT in patients with SCAD undergoing elective PCI. In this pilot paper initial single-centre results of interim analysis of the first 50 patients was reported. This initial interim analysis was pre-specified to assess the feasibility of integrating the rapid point-of-care $\mathrm{PFT}$ and genotyping into the routine PCI practice, as well as to evaluate the safety of more potent antiplatelet drug administration among patients with stable angina.

\section{Methods}

\section{Selection of patients}

The ONSIDE TEST Pilot study included patients treated at the Invasive Cardiology Unit of the $1^{\text {st }}$ Department of Cardiology, Medical University of Warsaw (Poland). Patients with stable coronary disease, between 18 and 75 years of age scheduled for an elective PCI with stent implantation were invited to participate in the study. The exclusion criteria comprised elevation of concentrations of myocardial necrosis enzyme at baseline, anticipated administration of glycoprotein IIb/IIIa inhibitors, usage of rotational atherectomy, intervention in chronic total occlusion or bifurcation lesions, low platelet count $(<70,000 / \mu \mathrm{L})$, high bleeding risk, coronary artery bypass surgery in last 3 months, severe chronic renal failure (estimated glomerular filtration rate $<30 \mathrm{~mL} / \mathrm{min}$ ), requirement for oral anticoagulation (warfarin, dabigatran, apixaban, rivaroxaban etc.), history of stroke or transient ischemic attack, weight $<60 \mathrm{~kg}$, known bleeding diathesis, hematocrit of $<30 \%$ or $>52 \%$ and pregnancy [14].

\section{Financing and bioethics approval}

The trial was sponsored by an independent research grant obtained from the Young Scientists Club 30 of the Polish Cardiac Society. The protocol was approved by the Bioethics Committee of the Medical University of Warsaw (Poland) in compliance with the Declaration of Helsinki.

\section{Endpoints}

The primary efficacy outcome measure was the incidence of periprocedural myocardial injury defined as elevation of troponin I $>1 \times 99^{\text {th }}$ percentile upper limit of norm (ULN), but $<5 \times 99^{\text {th }}$ percentile ULN or elevation of troponin I $>5 \times$ ULN in the absence of angiographic or imaging findings of ischemia. The secondary outcome measures were maximum level of CK-MB elevation within $24 \mathrm{~h}$ after PCI, maximum troponin elevation within $24 \mathrm{~h}$ after PCI, the prevalence of periprocedural myocardial infarction, prevalence of periprocedural myocardial biomarker leak was understood as any 
increase of myocardial necrotic enzymes above ULN. The periprocedural myocardial infarction was defined as troponin elevation $5 \times>99^{\text {th }}$ percentile ULN and one of the following: 1 ) chest pain exceeding $20 \mathrm{~min}$; 2) ischemic ST changes or new pathological $Q$ waves; 3) angiographic evidence of flow limiting complication; or 4) imaging evidence of myocardial ischemia. The safety endpoints included the risk of Bleeding Academic Research Consortium (BARC)-defined type 3 (clinical, laboratory, and/or imaging evidence of bleeding, with healthcare provider responses) and type 5 (fatal) bleeds happening within 7 and 30 days of PCI; and the rate of cardiac death, myocardial infarction, definite or probable stent thrombosis or urgent repeat revascularization within 30 days [15].

\section{Study design}

Patients who agreed to participate in the study and signed written informed consent were randomized using an electronic randomization tool for iPhone [Randomizer for Clinical Trial, MEDSHARING, Fontenay Sous Bois, France] to three arms: 1) phenotyping arm, 2) genotyping arm and 3) control arm [16]. All patients were on aspirin $75 \mathrm{mg}$ daily and on clopidogrel $75 \mathrm{mg}$ daily or received a loading dose of clopidogrel $600 \mathrm{mg}$ at least $6 \mathrm{~h}$ before testing. Patients in the phenotyping arm had their platelet reactivity checked using the point-of-care VerifyNow $\mathrm{P}_{2} \mathrm{Y}_{12}$ assay (Accumetrics, San Diego, US). Results were available within $5 \mathrm{~min}$, values above the cutoff point of 208 platelet reactivity units (PRU) indicated inadequate platelet inhibition and a mandatory loading dose of prasugrel $60 \mathrm{mg}$ was administered followed by a daily dose of $10 \mathrm{mg}$; other patients continued on clopidogrel. In the genotyping arm, the poor responders to clopidogrel were identified by the rapid, point-of-care Spartan RX CYP2C19 System (Spartan Bioscience Inc., Ottawa, Canada). Carriers of at least one copy of the CYP2C19*2 received a loading dose of prasugrel $60 \mathrm{mg}$ with a following $10 \mathrm{mg}$ daily [14].

\section{Statistical analysis}

Statistical analysis was conducted using IBM SPSS Statistics, version 21.0 (IBM, New York). The statistical analysis was based on an intentionto-treat population Shapiro-Wilk test which was used to check for normal distribution of continuous variables. Continuous variables were presented as mean \pm one standard deviation (SD) or median depending on distribution. Groups were compared with t-Student or Mann-Whitney tests, respectively. Nominal variables were shown as percentage or frequencies, and compared using the Fisher's exact test. P-values lower than 0.05 were considered as statistically significant.

\section{Results}

Overall 50 patients, who were scheduled for an elective PCI with stent implantation were randomized between December 2012, and November 2014. Four patients had to be excluded from the final analysis: two received ticagrelor before platelet function testing and two withdrew the informed consent. This was a high-risk population as per clinical characteristic with excessive prevalence of diabetes (39\%), hypertension (70\%), hyperlipidemia (70\%), heart failure (37\%), history of smoking (93\%), or previous myocardial infarction (59\%). Before admission most patients were on clopidogrel (76\%) and all on aspirin. There were no significant differences in the baseline clinical characteristics between the three study arms (Table 1).

The bedside testing was performed in all patients $8 \pm 1.2 \mathrm{~h}$ before PCI. Genotyping took $60 \mathrm{~min}$ and the test had to be repeated for $2 \mathrm{pa}-$ tients due to inconclusive results. The mean PFT time was $4 \mathrm{~min}$. Nurses or physicians performed all tests and no input from trained laboratory staff was needed.

The genotyping revealed that $15(32.6 \%)$ patients had at least one copy of the loss-of-function (CYP2C19*2) allele, of those $2(4.3 \%)$ were homozygous. At baseline, in the entire population the mean PRU was $157.5 \pm 73.55,11(24 \%)$ patients had high on-treatment platelet reactivity according to the prespecified cutoff value of PRU $>208$ (Table 2). Based on the point-of-care testing 5 (32\%) patients in the genotyping arm and $2(13 \%)$ patients in the PFT arm were identified as poor clopidogrel metabolizers and received loading dose of prasugrel at least $2 \mathrm{~h}$ before the scheduled PCI. No patient in the control arm was given prasugrel regardless of the geno-/phenotyping profile.

During the PCI most patients received 1 DES $(83 \%)$ in left anterior descending artery $(46 \%)$ (Table 3). Lesion preparation with predilatation was performed in $98 \%$ of cases; a balloon postdilatation was done in 1 of 5 patients. There were no major differences in terms of the procedural characteristics, except a numerically longer time of total vessel occlusion during intervention in the control group (Table 3).

The periprocedural platelet reactivity was significantly lower in the genotyping $(80 \pm 49.0$ $\mathrm{PRU})$ and phenotyping $(36.5 \pm 47.0 \mathrm{PRU})$ arms 
Table 1. Baseline clinical characteristics.

\begin{tabular}{|c|c|c|c|}
\hline & Genotyping ( $n=16)$ & Aggregometry $(n=16)$ & Control $(n=14)$ \\
\hline Age [years] & $61.2 \pm 10.2$ & $61 \pm 6.54$ & $63.5 \pm 5.64$ \\
\hline Female gender & $7(44 \%)$ & $6(38 \%)$ & $5(36 \%)$ \\
\hline Height $[\mathrm{cm}]$ & $170.5 \pm 6.42$ & $171.7 \pm 9.35$ & $170.9 \pm 6.66$ \\
\hline Weight [kg] & $84.8 \pm 13.41$ & $87.1 \pm 18.76$ & $85.5 \pm 16.14$ \\
\hline Body mass index $\left[\mathrm{kg} / \mathrm{m}^{2}\right]$ & $31.7 \pm 5.92$ & $28.4 \pm 2.56$ & $25.3 \pm 3.36$ \\
\hline \multicolumn{4}{|l|}{ Cardiac risk factors } \\
\hline Symptomatic stable CAD: & $16(100 \%)$ & $11(69 \%)$ & $11(79 \%)$ \\
\hline $\operatorname{ccs} 1$ & $5(29.4 \%)$ & $5(35.7 \%)$ & $7(46.7 \%)$ \\
\hline $\operatorname{ccs} 2$ & $8(47.1 \%)$ & $4(28.6 \%)$ & $5(33.3 \%)$ \\
\hline $\operatorname{ccs} 3$ & $4(23.5 \%)$ & $2(14.3 \%)$ & $0(0 \%)$ \\
\hline Hypertension & $11(69 \%)$ & $10(63 \%)$ & $11(79 \%)$ \\
\hline Diabetes mellitus & $7(44 \%)$ & $4(25 \%)$ & $7(50 \%)$ \\
\hline Hyperlipidemia & $13(82 \%)$ & $10(63 \%)$ & $9(65 \%)$ \\
\hline Atrial fibrillation & $1(7 \%)$ & $3(19 \%)$ & $3(22 \%)$ \\
\hline Heart failure (NYHA II-III) & $5(32 \%)$ & $6(38 \%)$ & $6(43 \%)$ \\
\hline LVEF [\%] & $45 \pm 16.9$ & $44 \pm 15.8$ & $50 \pm 11.7$ \\
\hline COPD & $1(7 \%)$ & $2(13 \%)$ & $2(15 \%)$ \\
\hline Smoking status & $13(82 \%)$ & $16(100 \%)$ & $14(100 \%)$ \\
\hline Habitual smoker & $4(25 \%)$ & $6(38 \%)$ & $4(29 \%)$ \\
\hline Ex-smoker & $9(57 \%)$ & $10(63 \%)$ & $10(72 \%)$ \\
\hline Non-smoker & $3(19 \%)$ & $0(0 \%)$ & $0(0 \%)$ \\
\hline Previous myocardial infarction & $9(57 \%)$ & $11(69 \%)$ & $7(50 \%)$ \\
\hline Anterior wall & $1(7 \%)$ & $5(32 \%)$ & $3(22 \%)$ \\
\hline Lateral wall & $2(13 \%)$ & $1(7 \%)$ & $0(0 \%)$ \\
\hline Inferior wall & $5(32 \%)$ & $5(32 \%)$ & $3(22 \%)$ \\
\hline Posterior wall & $1(7 \%)$ & $0(0 \%)$ & $1(8 \%)$ \\
\hline Previous $\mathrm{PCl}$ & $9(57 \%)$ & $9(57 \%)$ & $7(50 \%)$ \\
\hline \multicolumn{4}{|l|}{ Laboratory } \\
\hline CK-MB [ng/mL] & $0.60(0.35-1.25)$ & $1.05(0.62-1.97)$ & $1.60(0.65-2.65)$ \\
\hline Troponin I [ng/mL] & $0.002(0.000-0.009)$ & $0.007(0.000-0.019)$ & $0.014(0.000-0.022)$ \\
\hline Creatinine $[\mathrm{mg} / \mathrm{dL}]$ & $0.9 \pm 0.20$ & $1.0 \pm 0.20$ & $1.0 \pm 0.32$ \\
\hline eGFR $\left[\mathrm{mL} / \mathrm{min} / 1.73 \mathrm{~m}^{2}\right]$ & $57(49-59)$ & $59(51-60)$ & $58(51-60)$ \\
\hline Red blood cells $\left[10^{6} / \mu \mathrm{L}\right]$ & $4.6 \pm 0.35$ & $4.7 \pm 0.51$ & $4.8 \pm 0384$ \\
\hline Hamoglobin [g/dL] & $14.5 \pm 0.97$ & $14.6 \pm 1.22$ & $14.2 \pm 1.14$ \\
\hline Platelets $\left[10^{3} / \mu \mathrm{L}\right]$ & $241 \pm 68.9$ & $245 \pm 79.8$ & $219 \pm 80.3$ \\
\hline INR & $1.00 \pm 0.069$ & $1.00 \pm 0.055$ & $0.98 \pm 0.055$ \\
\hline APTT [s] & $27 \pm 2.2$ & $32 \pm 3.7$ & $29 \pm 2.4$ \\
\hline AST [U/L] & $21.5 \pm 5.92$ & $23.9 \pm 6.54$ & $24.8 \pm 7.52$ \\
\hline ALT [U/L] & $29.7 \pm 11.67$ & $33.1 \pm 12.95$ & $45.62 \pm 67.126$ \\
\hline \multicolumn{4}{|l|}{ Baseline pharmacotherapy } \\
\hline Aspirin & $16(100 \%)$ & $13(82 \%)$ & $14(100 \%)$ \\
\hline Clopidogrel & $14(88 \%)$ & $12(75 \%)$ & $9(65 \%)$ \\
\hline Statin & $16(100 \%)$ & $13(82 \%)$ & $13(93 \%)$ \\
\hline Beta-blocker & $16(100 \%)$ & $12(75 \%)$ & $12(86 \%)$ \\
\hline ACE-I or ARB & $15(94 \%)$ & $12(75 \%)$ & $12(86 \%)$ \\
\hline Calcium channel blocker & $1(7 \%)$ & $1(7 \%)$ & $0(0 \%)$ \\
\hline Proton pump inhibitor & $5(32 \%)$ & $8(50 \%)$ & $7(50 \%)$ \\
\hline
\end{tabular}

Data are presented as count and percentage (\%) or mean \pm standard deviation; CAD - coronary artery disease; CCS - Canadian Cardiovascular Society; NYHA — New York Heart Association; LVEF — left ventricular ejection fraction; COPD — chronic obstructive pulmonary disease; $\mathrm{PCl}$ - percutaneous coronary intervention; CK-MB - creatine kinase muscle-brain; eGFR - estimated glomerular filtration rate; INR - international normalized ratio; APTT — activated partial thromboplastin time; AST — aspartate aminotransferase; ALT — alanine aminotransferase; ACE-I — angiotensin-converting enzyme inhibitor; ARB — angiotensin receptor blocker 
Table 2. Platelet function, genotype and pharmacotherapy.

\begin{tabular}{lccc}
\hline & $\begin{array}{c}\text { Genotyping } \\
\text { (n=16) }\end{array}$ & $\begin{array}{c}\text { Aggregometry } \\
\text { (n= 16) }\end{array}$ & $\begin{array}{c}\text { Control } \\
(\mathbf{n}=14)\end{array}$ \\
\hline Before testing & & & \\
Baseline pharmacokinetic response, platelet reactivity [PRU] & $160.5 \pm 61.36$ & $138.4 \pm 87.7$ & $177.5 \pm 67.8$ \\
High platelet reactivity, PRU > 208 & $2(13 \%)$ & $5(32 \%)$ & $4(29 \%)$ \\
CYP2C19*2 carrier (heterozygote) & $5(32 \%)$ & $4(25 \%)$ & $4(29 \%)$ \\
CYP2C19 carrier (homozygote) & $1(7 \%)$ & $0(0 \%)$ & $1(8 \%)$ \\
After testing & & & $0(0 \%)$ \\
Switch to prasugrel & $5(32 \%)$ & $2(13 \%)$ & 0 \\
\hline
\end{tabular}

Data are presented as count and percentage $(\%)$ or mean \pm standard deviation; PRU — platelet reactivity units

Table 3. Procedural characteristics.

\begin{tabular}{|c|c|c|c|}
\hline & $\begin{array}{l}\text { Genotyping } \\
(n=16)\end{array}$ & $\begin{array}{l}\text { Aggregometry } \\
\qquad(\mathrm{n}=16)\end{array}$ & $\begin{array}{l}\text { Control } \\
(n=14)\end{array}$ \\
\hline \multicolumn{4}{|l|}{ Lesion location } \\
\hline Left main & $0(0 \%)$ & $1(7 \%)$ & $0(0 \%)$ \\
\hline Left anterior descending artery & $7(44 \%)$ & $8(50 \%)$ & $6(43 \%)$ \\
\hline Circumflex artery & $3(19 \%)$ & $2(13 \%)$ & $4(29 \%)$ \\
\hline Right coronary artery & $3(19 \%)$ & $3(19 \%)$ & $1(8 \%)$ \\
\hline \multicolumn{4}{|l|}{ Number of stents } \\
\hline One & $11(69 \%)$ & $12(75 \%)$ & $11(79 \%)$ \\
\hline Two & $5(32 \%)$ & $4(25 \%)$ & $3(22 \%)$ \\
\hline Drug eluting stent & $14(88 \%)$ & $13(82 \%)$ & $11(79 \%)$ \\
\hline Bare metal stent & $2(13 \%)$ & $3(19 \%)$ & $3(22 \%)$ \\
\hline Direct stenting & $0(0 \%)$ & $1(7 \%)$ & $0(0 \%)$ \\
\hline Stent postdilatation & $3(19 \%)$ & $3(19 \%)$ & $3(22 \%)$ \\
\hline Total length of stent $[\mathrm{mm}]$ & $27.1 \pm 13.79$ & $26.1 \pm 14.01$ & $28.8 \pm 23.18$ \\
\hline Total vessel occlusion time [s] & $79 \pm 40.1$ & $102 \pm 53.6^{\#}$ & $68 \pm 23.4^{\#}$ \\
\hline Periprocedural pain & $1(7 \%)$ & $1(7 \%)$ & $1(8 \%)$ \\
\hline Intravascular ultrasound & $1(7 \%)$ & $1(7 \%)$ & $0(0 \%)$ \\
\hline Optical coherence tomography & $1(7 \%)$ & $1(7 \%)$ & $0(0 \%)$ \\
\hline \multicolumn{4}{|l|}{ Periprocedural pharmacotherapy } \\
\hline Unfractionated heparin $\left[10^{3}\right.$ units $]$ & $6.9 \pm 2.34$ & $8.1 \pm 1.94)$ & $8.0 \pm 1.73$ \\
\hline Abciximab & $1(7 \%)$ & $0(0 \%)$ & $0(0 \%)$ \\
\hline Eptifibatide & $1(7 \%)$ & $0(0 \%)$ & $0(0 \%)$ \\
\hline Good angiographic result (TIMI 3) & $15(94 \%)$ & $16(100 \%)$ & $13(93 \%)$ \\
\hline
\end{tabular}

Data are presented as count and percentage $(\%)$ or mean \pm standard deviation; ${ }^{*} \mathrm{p}=0.066$

as compared to the control arm (176 $\pm 67.8 \mathrm{PRU})$, $(\mathrm{p}=0.01$ and $\mathrm{p}=0.03$, respectively).

The periprocedural myocardial injury appeared in $17(37 \%)$ patients of the entire study population. There were no statistically significant differences in terms of the periprocedural myocardial injury in the control, aggregometry and genotyping groups $(35.7 \%, 37.5 \%$, and $40 \%$, respectively, $\mathrm{p}=0.97)$ (Table 4). The median peak CK-MB elevation within $24 \mathrm{~h}$ after PCI was $2.0 \mathrm{ng} / \mathrm{mL}$. Seven patients in the control arm, 9 in the phenotyping arm and 5 in the genotyping arm had CK-MB above the median. 
Table 4. Main study outcomes.

\begin{tabular}{|c|c|c|c|c|c|c|}
\hline & $\begin{array}{l}\text { Genotyping } \\
(\mathrm{n}=16)\end{array}$ & $\begin{array}{l}\text { Aggregometry } \\
(n=16)\end{array}$ & $\begin{array}{l}\text { Control } \\
(n=14)\end{array}$ & $\begin{array}{l}\text { P: Gen } \\
\text { vs. Agg* }\end{array}$ & $\begin{array}{l}\text { P: Agg } \\
\text { vs. Con* }\end{array}$ & $\begin{array}{l}\text { P: Gen } \\
\text { vs. Con* }\end{array}$ \\
\hline $\begin{array}{l}\text { Pharmacokinetic response } \\
30 \text { min after } \mathrm{PCl} \text { [PRU] }\end{array}$ & $80.3 \pm 49$ & $36.5 \pm 47$ & $177.5 \pm 67.8$ & 0.39 & 0.01 & 0.03 \\
\hline Periprocedural myocardial injury & $40.0 \%$ & $37.5 \%$ & $35.7 \%$ & 1.00 & 1.00 & 1.00 \\
\hline Peak CK-MB elevation [ng/mL] & $1.3(0.7-4.2)$ & $2.4(1.1-4.1)$ & $2.1(1.1-3.5)$ & 0.82 & 0.72 & 0.85 \\
\hline $\begin{array}{l}\text { Periprocedural MI [cTnl }>5 \times \\
\text { ULN + symptoms] }\end{array}$ & $6.3 \%$ & $0.0 \%$ & $0.0 \%$ & 0.31 & 1.00 & 0.34 \\
\hline $\begin{array}{l}\text { Periprocedural myocardial } \\
\text { biomarker leak [cTnl or } \\
\text { CK-MB }>1 \times \text { ULN] }\end{array}$ & $80.0 \%$ & $81.3 \%$ & $75.0 \%$ & 1.00 & 1.00 & 1.00 \\
\hline Peak Tnl elevation $[\mathrm{ng} / \mathrm{mL}]$ & $\begin{array}{c}1.73 \\
(0.41-3.16)\end{array}$ & $\begin{array}{c}1.92 \\
(0.82-5.99)\end{array}$ & $\begin{array}{c}1.54 \\
(0.54-5.00)\end{array}$ & 0.33 & 0.36 & 0.32 \\
\hline $\begin{array}{l}\text { BARC } 3 \text { or } 5 \text { bleeding } \\
\text { (within } 7 \text { days) }\end{array}$ & $0.0 \%$ & $12.5 \%$ & $0.0 \%$ & 0.16 & 0.17 & 1.00 \\
\hline $\begin{array}{l}\text { Cardiac death, MI, stent } \\
\text { thrombosis, revascularization } \\
\text { (within } 30 \text { days) }\end{array}$ & $6.3 \%$ & $0.0 \%$ & $0.0 \%$ & 0.31 & 1.00 & 0.34 \\
\hline
\end{tabular}

Data are presented as count and percentage (\%), median and interquartile range or mean \pm standard deviation; Agg - aggregometry; Gen - genotyping; $\mathrm{PCl}$ - percutaneous coronary intervention; PRU - platelet reactivity units; CK-MB - creatine kinase muscle-brain; $\mathrm{MI}$ - myocardial infarction; cTnl - cardiac troponin I; ULN - upper normal limit; BARC — Bleeding Academic Research Consortium

The median peak troponin elevation within $24 \mathrm{~h}$ was $0.19 \mathrm{ng} / \mathrm{mL}$. Seven patients in the control arm, 8 in the phenotyping arm and 8 in the genotyping arm had CK-MB above the median. There were no differences in the prevalence of periprocedural myocardial infarction, myocardial biomarker leak, and risk of major bleeding and MACE at the 30-day follow-up. Main study outcomes are presented in Table 4.

\section{Discussion}

In research of the literature, this is the first study aiming to compare two point-of-care testing methods in a head-to-head manner with standard care in patients undergoing elective PCI for SCAD. The present report confirmed safety and feasibility of personalized point-of-care strategy in this patient population. Previous studies have assessed only one type point-of-care testing and did not evaluate the platelet inhibition before and during PCI. It is worth underlining that the presented results are based on one third of the planned population and should be examined carefully. In the present study no differences were found in terms of peak CK-MB within $24 \mathrm{~h}$ after PCI between the three study populations. There are no other studies that would assess the myocardial injury in relation to type of antiplatelet drug used. However there is evidence that higher platelet reactivity during PCI is related to periprocedural myonecrosis [17] and worse prognosis [18-25].

There was a significantly stronger platelet inhibition in the genotyping and PFT groups as expressed by the PRU values than in the control group. This is in line with pharmacodynamic data from the Testing platelet Reactivity In patients undergoing elective stent placement on clopidogrel to Guide alternative thErapy with pRasugrel (TRIGGER PCI) study that demonstrated the efficacy of prasugrel in overcoming HTPR on clopidogrel in patients with SCAD [12].

The number of heterozygous carriers of the CYP2C19*2 allele observed in this study confirms the observations from previous studies [11, 26-28]. It should be noted that in the genotyping group there was a numerically higher rate of periprocedural myocardial injury than in the control group. Nevertheless, it was mainly driven by procedural mechanical complications (severe artery dissection) and thus, cannot be directly associated with inadequate response to antiplatelet agents.

The data from randomized clinical trials confirmed that stronger platelet inhibition in acute coronary syndrome patients treated with PCI reduces the rate of ischemic events, with an increase in risk of bleeding complications [29-32]. However, such an association has been less apparent in patients with stable angina [33].

Dual antiplatelet tailored strategy based on bedside aggregometry was previously studied 
by Collet et al. [34], however in the Assessment by a Double Randomization of a Conventional Antiplatelet Strategy versus a Monitoring-guided Strategy for Drug-Eluting Stent Implantation and of Treatment Interruption versus Continuation One Year after Stenting (ARCTIC) trial pre-PCI intensification of $\mathrm{P}_{2} \mathrm{Y}_{12}$ and glycoprotein IIb/IIIa inhibition when monitoring with VerifyNow $\mathrm{P}_{12}$ aggregometry revealed a poor response to clopidogrel did not show any improvement in ischemic or safety outcomes with a strategy of monitoring and drug adjustment as compared with a conventional treatment strategy [34]. Similarly, the TRIGGER PCI study, comparing prasugrel vs. clopidogrel in the low risk population of patients screened with the VerifyNow assay after elective uncomplicated angioplasty with DES implantation was stopped prematurely for futility [12]. In the group of 236 patients with complete 6-month follow-up only one primary endpoint of cardiac death or myocardial infarction had occurred, accounting for an incidence of $0.4 \%$. As the rate of MACE in the population of SCAD patients is minimal in the era of new generation DES, it might not be feasible to perform an appropriately sized study assessing clinical endpoints with sufficient statistical power. Having evidence for a gradual increase in mortality risk with each increment of CK-MB plasma concentration after PCI [35-37], it appears that an approach involving assessment of surrogate endpoint (i.e. myocardial injury) might be more efficacious in verification of tailored antiplatelet therapy hypothesis in low-risk populations. Nevertheless, the threshold beyond which biomarker elevations are clinically significant still needs to be determined, presumably with the employment of high-resolution imaging to verify the extent of myonecrosis [38, 39]. The plasma levels of myocardial injury biomarkers were comparable in all three-study arms in this study. However, the study is still ongoing and will continue until 362 subjects are randomized, according to the already reported sample size analyses.

Notably, the present investigation provided also novel data on the prevalence of periprocedural myocardial infarction in the elective PCI patient population, that might also constitute additional reference for other investigators, as the evidence on the incidence of periprocedural myocardial injury among SCAD patients undergoing invasive treatment remains unsatisfactory.

Finally, in this pilot study, it was also confirmed that the feasibility and convenience of point-of-care testing methods in the assessment of response to antiplatelet therapy in patients undergoing elective PCI. Both phenotyping and genotyping could have been performed by a physician or nurse subsequent to a short training and the results could have been achieved quickly, especially in cases of aggregometry.

\section{Limitations of the study}

The main limitation of this study is a small number of enrolled patients. Another limitation is a potential lack of sensitivity of the primary end point, which may be driven by the incidence of periprocedural technical complications apart from adequate platelet inhibition. However, the approach enclosing exclusion of periprocedural myocardial infarction from the study endpoint analysis has already proved to be ineffective [12] and the optimal antiplatelet therapy might potentially attenuate ischemic complications of PCI. Furthermore, a limitation of this trial is also its open-label design, which was the consequence of numerous interventions occurring over the course of this study.

\section{Conclusions}

In the present study, individualization of antiplatelet therapy on the basis of point-of-care platelet function testing by switching to prasugrel in SCAD patients with high on-clopidogrel platelet reactivity resulted in a consistent decrease in platelet reactivity, achieving a level similar to that observed in clopidogrel responsive subjects. This pilot study confirms feasibility of bedside genotyping and phenotyping testing in everyday clinical practice.

\section{Conflict of interest: None declared}

\section{References}

1. De Bruyne B, Pijls NHJ, Kalesan B, et al. FAME 2 Trial Investigators. Fractional flow reserve-guided PCI versus medical therapy in stable coronary disease. N Engl J Med. 2012; 367(11): 991-1001, doi: 10.1056/NEJMoa1205361, indexed in Pubmed: 22924638.

2. Weintraub WS, Spertus JA, Kolm P, et al. COURAGE Trial Research Group. Effect of PCI on quality of life in patients with stable coronary disease. N Engl J Med. 2008; 359(7): 677-687, doi: 10.1056/NEJMoa072771, indexed in Pubmed: 18703470.

3. Pawęska J, Macioch T, Perkowski P, et al. Direct healthcare costs and cost-effectiveness of acute coronary syndrome secondary prevention with ticagrelor compared to clopidogrel: economic evaluation from the public payer's perspective in Poland based on the PLATO trial results. Kardiol Pol. 2014; 72(9): 823-830, doi: 10.5603/KP.a2014.0106, indexed in Pubmed: 24846362. 
4. Patti G, Colonna G, Pasceri V, et al. Randomized trial of high loading dose of clopidogrel for reduction of periprocedural myocardial infarction in patients undergoing coronary intervention: results from the ARMYDA-2 (Antiplatelet therapy for Reduction of MYocardial Damage during Angioplasty) study. Circulation. 2005; 111(16): 2099-2106, doi: 10.1161/01.CIR.0000161383.06692.D4, indexed in Pubmed: 15750189.

5. Ellis SG, Chew D, Chan A, et al. Death following creatine kinase$\mathrm{MB}$ elevation after coronary intervention: identification of an early risk period: importance of creatine kinase-MB level, completeness of revascularization, ventricular function, and probable benefit of statin therapy. Circulation. 2002; 106(10): 1205-1210, indexed in Pubmed: 12208794.

6. Michalak M, Huczek Z, Filipiak KJ, et al. Periprocedural myocardial damage during percutaneous coronary intervention: a point-of-care platelet testing and intravascular ultrasound/virtual histology study. Kardiol Pol. 2013; 71(4): 325-333, doi: 10.5603/ KP.2013.0059, indexed in Pubmed: 23788337.

7. Bliden KP, DiChiara J, Tantry US, et al. Increased risk in patients with high platelet aggregation receiving chronic clopidogrel therapy undergoing percutaneous coronary intervention: is the current antiplatelet therapy adequate? J Am Coll Cardiol. 2007; 49(6): 657-666, doi: 10.1016/j.jacc.2006.10.050, indexed in Pubmed: 17291930.

8. Aradi D, Komócsi A, Vorobcsuk A, et al. Prognostic significance of high on-clopidogrel platelet reactivity after percutaneous coronary intervention: systematic review and meta-analysis. Am Heart J. 2010; 160(3): 543-551, doi: 10.1016/j.ahj.2010.06.004, indexed in Pubmed: 20826265.

9. Stone GW, Witzenbichler B, Weisz G, et al. ADAPT-DES Investigators. Platelet reactivity and clinical outcomes after coronary artery implantation of drug-eluting stents (ADAPT-DES): a prospective multicentre registry study. Lancet. 2013; 382(9892): 614-623, doi: 10.1016/S0140-6736(13)61170-8, indexed in Pubmed: 23890998.

10. Price MJ, Angiolillo DJ, Teirstein PS, et al. Platelet reactivity and cardiovascular outcomes after percutaneous coronary intervention: a time-dependent analysis of the Gauging Responsiveness with a VerifyNow P2Y12 assay: Impact on Thrombosis and Safety (GRAVITAS) trial. Circulation. 2011; 124(10): 1132-1137, doi: 10.1161/CIRCULATIONAHA.111.029165, indexed in Pubmed: 21875913.

11. Mega JL, Simon T, Collet JP, et al. Reduced-function CYP2C19 genotype and risk of adverse clinical outcomes among patients treated with clopidogrel predominantly for PCI: a meta-analysis. JAMA. 2010; 304(16): 1821-1830, doi: 10.1001/jama.2010.1543, indexed in Pubmed: 20978260.

12. Trenk D, Stone GW, Gawaz M, et al. A randomized trial of prasugrel versus clopidogrel in patients with high platelet reactivity on clopidogrel after elective percutaneous coronary intervention with implantation of drug-eluting stents: results of the TRIGGER-PCI (Testing Platelet Reactivity In Patients Undergoing Elective Stent Placement on Clopidogrel to Guide Alternative Therapy With Prasugrel) study. J Am Coll Cardiol. 2012; 59(24): 2159-2164, doi: 10.1016/j.jacc.2012.02.026, indexed in Pubmed: 22520250.

13. Wallentin L, James S, Storey RF, et al. PLATO investigators. Effect of CYP2C19 and ABCB1 single nucleotide polymorphisms on outcomes of treatment with ticagrelor versus clopidogrel for acute coronary syndromes: a genetic substudy of the PLATO trial. Lancet. 2010; 376(9749): 1320-1328, doi: 10.1016/S01406736(10)61274-3, indexed in Pubmed: 20801498.
14. Kołtowski Ł, Aradi D, Huczek Z, et al. Study design and rationale for Optimal aNtiplatelet pharmacotherapy guided by bedSIDE genetic or functional TESTing in elective percutaneous coronary intervention patients (ONSIDE TEST): a prospective, open-label, randomised parallel-group multicentre trial (NCT01930773). Kardiol Pol. 2016; 74(4): 372-379, doi: 10.5603/KP.a2015.0172, indexed in Pubmed: 26365936.

15. Steg PG, Huber K, Andreotti F, et al. Bleeding in acute coronary syndromes and percutaneous coronary interventions: position paper by the Working Group on Thrombosis of the European Society of Cardiology. Eur Heart J. 2011; 32(15): 1854-1864, doi: 10.1093/eurheartj/ehr204, indexed in Pubmed: 21715717.

16. MEDSHARING. Randomizer for Clinical Trial. https://itunes.apple.com/en/app/randomizer-for-clinical-trial/id578254014? $\mathrm{mt}=8$.

17. Eshtehardi P, Windecker S, Cook S, et al. Dual low response to acetylsalicylic acid and clopidogrel is associated with myonecrosis and stent thrombosis after coronary stent implantation. Am Heart J. 2010; 159(5): 891-898.e1, doi: 10.1016/j.ahj.2010.02.025, indexed in Pubmed: 20435201.

18. Sibbing D, Braun S, Morath T, et al. Platelet reactivity after clopidogrel treatment assessed with point-of-care analysis and early drug-eluting stent thrombosis. J Am Coll Cardiol. 2009; 53(10): 849-856, doi: 10.1016/j.jacc.2008.11.030, indexed in Pubmed: 19264241.

19. Stone GW, Witzenbichler B, Weisz G, et al. ADAPT-DES Investigators. Platelet reactivity and clinical outcomes after coronary artery implantation of drug-eluting stents (ADAPT-DES): a prospective multicentre registry study. Lancet. 2013; 382(9892): 614-623, doi: 10.1016/S0140-6736(13)61170-8, indexed in Pubmed: 23890998.

20. Breet NJ, van Werkum JW, Bouman HJ, et al. Comparison of platelet function tests in predicting clinical outcome in patients undergoing coronary stent implantation. JAMA. 2010; 303(8): 754-762, doi: 10.1001/jama.2010.181, indexed in Pubmed: 20179285.

21. Cuisset T, Frere C, Quilici J, et al. Predictive values of posttreatment adenosine diphosphate-induced aggregation and vasodilator-stimulated phosphoprotein index for stent thrombosis after acute coronary syndrome in clopidogrel-treated patients. Am J Cardiol. 2009; 104(8): 1078-1082, doi: 10.1016/j. amjcard.2009.06.007, indexed in Pubmed: 19801028.

22. Parodi G, Marcucci R, Valenti R, et al. High residual platelet reactivity after clopidogrel loading and long-term cardiovascular events among patients with acute coronary syndromes undergoing PCI. JAMA. 2011; 306(11): 1215-1223, doi: 10.1001/ jama.2011.1332, indexed in Pubmed: 21934054.

23. Geisler T, Langer H, Wydymus M, et al. Low response to clopidogrel is associated with cardiovascular outcome after coronary stent implantation. Eur Heart J. 2006; 27(20): 2420-2425, doi: 10.1093/eurheartj/ehl275, indexed in Pubmed: 17005534.

24. Angiolillo DJ, Bernardo E, Zanoni M, et al. Impact of platelet reactivity on cardiovascular outcomes in patients with type 2 diabetes mellitus and coronary artery disease. J Am Coll Cardiol. 2007; 50(16): 1541-1547, doi: 10.1016/j.jacc.2007.05.049, indexed in Pubmed: 17936152.

25. Gurbel PA, Antonino MJ, Bliden KP, et al. Platelet reactivity to adenosine diphosphate and long-term ischemic event occurrence following percutaneous coronary intervention: a potential antiplatelet therapeutic target. Platelets. 2008; 19(8): 595-604, doi: 10.1080/09537100802351065, indexed in Pubmed: 19012177. 
26. Rideg O, Komócsi A, Magyarlaki T, et al. Impact of genetic variants on post-clopidogrel platelet reactivity in patients after elective percutaneous coronary intervention. Pharmacogenomics. 2011; 12(9): 1269-1280, doi: 10.2217/pgs.11.73, indexed in Pubmed: 21806387.

27. Hulot JS, Collet JP, Silvain J, et al. Cardiovascular risk in clopidogrel-treated patients according to cytochrome P450 2C19*2 loss-of-function allele or proton pump inhibitor coadministration: a systematic meta-analysis. J Am Coll Cardiol. 2010; 56(2): 134-143, doi: 10.1016/j.jacc.2009.12.071, indexed in Pubmed: 20620727.

28. Shuldiner AR, O'Connell JR, Bliden KP, et al. Association of cytochrome P450 2C19 genotype with the antiplatelet effect and clinical efficacy of clopidogrel therapy. JAMA. 2009; 302(8): 849-857, doi: 10.1001/jama.2009.1232, indexed in Pubmed: 19706858.

29. Mehta SR, Tanguay JF, Eikelboom JW, et al. CURRENT-OASIS 7 trial investigators. Double-dose versus standard-dose clopidogrel and high-dose versus low-dose aspirin in individuals undergoing percutaneous coronary intervention for acute coronary syndromes (CURRENT-OASIS 7): a randomised factorial trial. Lancet. 2010; 376(9748): 1233-1243, doi: 10.1016/S01406736(10)61088-4, indexed in Pubmed: 20817281.

30. Wallentin L, Becker RC, Budaj A, et al. PLATO Investigators. Ticagrelor versus clopidogrel in patients with acute coronary syndromes. N Engl J Med. 2009; 361(11): 1045-1057, doi: 10.1056/NEJMoa0904327, indexed in Pubmed: 19717846.

31. Cannon CP, Harrington RA, James S, et al. PLATelet inhibition and patient Outcomes Investigators. Comparison of ticagrelor with clopidogrel in patients with a planned invasive strategy for acute coronary syndromes (PLATO): a randomised double-blind study. Lancet. 2010; 375(9711): 283-293, doi: 10.1016/S01406736(09)62191-7, indexed in Pubmed: 20079528.

32. Wiviott SD, Braunwald E, McCabe $\mathrm{CH}$, et al. TRITON-TIMI 38 Investigators. Prasugrel versus clopidogrel in patients with acute coronary syndromes. N Engl J Med. 2007; 357(20): 2001-2015, doi: 10.1056/NEJMoa0706482, indexed in Pubmed: 17982182.

33. Rinaldi M, Kirtane A, Xu Ke, et al. Impact of point-of-care platelet function testing among patients with and without acute coronary syndromes undergoing PCI with drug-eluting stents: an adaptdes substudy. Journal of the American College of Cardiology. 2013; 61(10): E1857, doi: 10.1016/s0735-1097(13)61857-4.

34. Collet JP, Cayla G, Cuisset T, et al. Randomized comparison of platelet function monitoring to adjust antiplatelet therapy versus standard of care: rationale and design of the assessment with a double randomization of (1) a fixed dose versus a monitoringguided dose of aspirin and clopidogrel after DES implantation, and (2) treatment interruption versus continuation, 1 year after stenting (ARCTIC) study. Am Heart J. 2011; 161(1): 5-12.e5, doi: 10.1016/j.ahj.2010.09.029, indexed in Pubmed: 21167334.

35. Kong TQ, Davidson CJ, Meyers SN, et al. Prognostic implication of creatine kinase elevation following elective coronary artery interventions. JAMA. 1997; 277(6): 461-466, indexed in Pubmed: 9020269.

36. Ioannidis JPA, Karvouni E, Katritsis DG. Mortality risk conferred by small elevations of creatine kinase-MB isoenzyme after percutaneous coronary intervention. J Am Coll Cardiol. 2003; 42(8): 1406-1411, indexed in Pubmed: 14563583.

37. Ghazzal Z, Ashfaq S, Morris DC, et al. Prognostic implication of creatine kinase release after elective percutaneous coronary intervention in the pre-IIb/IIIa antagonist era. Am Heart J. 2003; 145(6): 1006-1012, doi: 10.1016/S0002-8703(03)00095-4, indexed in Pubmed: 12796756.

38. Lansky AJ, Stone GW. Periprocedural myocardial infarction: prevalence, prognosis, and prevention. Circ Cardiovasc Interv. 2010; 3(6): 602-610, doi: 10.1161/CIRCINTERVENTIONS.110.959080, indexed in Pubmed: 21156928.

39. Zimarino M, Affinito V. The prognosis of periprocedural myocardial infarction after percutaneous coronary interventions. Cardiovasc Revasc Med. 2013; 14(1): 32-36, doi: 10.1016/j.carrev.2012.10.006, indexed in Pubmed: 23164601. 